\title{
Predictors of Peak Troponin Level in Acute Coronary Syndromes: Prior Aspirin Use and SYNTAX Score
}

\author{
Hemal A. Bhatt, MD ${ }^{1}$ Dharmesh R. Sanghani, MD ${ }^{1}$ \\ George A. Fernaine, $\mathrm{MD}^{2}$ \\ ${ }^{1}$ Department of Internal Medicine, Lutheran Medical Center, \\ Brooklyn, New York \\ ${ }^{2}$ Department of Cardiology, Lutheran Medical Center, \\ Brooklyn, New York
}

David Lee, MD ${ }^{1} \quad$ Kell N. Julliard, MA ${ }^{1}$

\begin{abstract}
Address for correspondence Hemal A. Bhatt, MD, Department of Internal Medicine, Lutheran Medical Center, 150 55th Street, Brooklyn, NY 11220 (e-mail: cardiothorax@gmail.com).
\end{abstract}

Int J Angiol 2016;25:54-63.

\begin{abstract}
Keywords

- SYNTAX

- troponin

- acute coronary syndromes

- aspirin

- statin

- STEMI

- coronary artery disease

- cardiovascular

The peak troponin level has been associated with cardiovascular (CV) mortality and adverse $\mathrm{CV}$ events. The association of peak troponin with CV risk factors and severity and complexity of coronary artery disease remains unknown. We assessed the predictors of peak troponin in patients with acute coronary syndrome (ACS). This study aims to determine the predictors of peak troponin in ACS. Cardiac catheterization (CC) reports and electronic medical records from 2010 to 2013 were retrospectively reviewed. A total of 219 patients were eligible for the study. All major CV risk factors, comorbidities, laboratory data, CC indications, and coronary lesion characteristics were included. Univariate and multivariate regression analyses were done. On multivariate linear regression analysis, ST-elevation myocardial infarction $(p=0.001, \beta=65.16)$ and increasing synergy between percutaneous coronary intervention with Taxus and cardiac surgery (SYNTAX) score $(p=0.002, \beta=1.15)$ were associated with higher peak troponin. The Pearson correlation between SYNTAX score and peak troponin was $r=0.257, p=0.001$. History of daily aspirin use was associated with lower peak troponin ( $p=0.002, \beta=-24.32)$. Prior statin use $(p=0.321, \beta=-8.98)$ and the presence of $C V$ risk factors were not associated with peak troponin. Coronary artery disease severity and complexity, urgency of CC, and prior aspirin use are associated with peak troponin levels in ACS. Our findings may help predict patient population with ACS who would be at a greater risk for short- and long-term CV morbidity and mortality due to elevated peak troponin.
\end{abstract}

Acute coronary syndrome (ACS) refers to clinical symptoms consistent with acute myocardial ischemia and covers a spectrum of conditions ranging from unstable angina (UA), non-ST-elevation myocardial infarction (NSTEMI), and STEMI. ${ }^{1}$ In addition to chest discomfort and electrocardiogram changes, active myocardial ischemia leads to myocardial necrosis, which results in the release of cardiac-specific biomarkers such as troponin. ${ }^{2,3}$ Loss of functioning myocardium resulting from acute ischemic events leads to ventricu- lar dysfunction and poor outcomes. ${ }^{4}$ Troponin elevation has both the diagnostic and prognostic utility in ACS. Peak troponin level has been associated with short-term and long-term mortality, all-cause mortality, and adverse cardiovascular (CV) events in patients with ACS. ${ }^{5-9}$ Peak troponin has been correlated with infarct size in patients with STEMI. ${ }^{10}$ In patients with UA, higher peak troponin level has been associated with triple vessel disease and lesions with greater degree of stenosis. ${ }^{11,12}$ However, in the setting of STEMI and
Copyright @ 2016 by Thieme Medical Publishers, Inc., 333 Seventh Avenue, New York, NY 10001, USA. Tel: +1(212) 584-4662.
DOI http://dx.doi.org/ 10.1055/s-0035-1547396. ISSN 1061-1711. 
NSTEMI, the association of CV risk factors and the extent of coronary artery disease (CAD) with peak troponin remains unknown. Synergy between percutaneous coronary intervention with Taxus and cardiac surgery (SYNTAX) is an angiographic measure for grading the CAD complexity and severity. ${ }^{13}$ SYNTAX score grades the complexity of CAD based on characteristics such as number of lesions, coronary segments involved, lesion location, presence of calcification and thrombus, lesion length, and coronary dominance. ${ }^{14,15}$ This scoring system is used to determine optimal revascularization approaches, such as coronary bypass surgery or percutaneous coronary intervention $(\mathrm{PCI}) .{ }^{14,15}$ SYNTAX score has been used as a predictor of 1-year mortality and adverse cardiac events in ACS. ${ }^{16,17}$ Given that the peak troponin levels correlate with infarct size, we predict an association of severity and extent of CAD and peak troponin level in ACS. We, therefore, conducted a study to determine an association between peak troponin level and CV risk factors and severity and complexity of CAD in patients with ACS.

\section{Methods}

A retrospective cross-sectional study was conducted at an urban community teaching hospital in Brooklyn, NY. The study protocol was approved by the hospital's institutional review board, and a waiver of patient informed consent was granted. Electronic medical records, cardiac catheterization (CC) reports, and laboratory data were reviewed for the period of January 2010 to December 2013. CCs were performed by an interventional cardiologist, and only the patients presenting with ACS (STEMI, NSTEMI, and UA) were included in the study. Data on demographics and comorbidities were obtained from the medical records and also based on specific criteria for a given comorbidity. Patients were grouped based on the presence or absence of $\mathrm{CV}$ risk factors such as hypertension (use of antihypertensive medications), smoking (previous or current cigarette use), and hypercholesterolemia. Patients were further stratified based on their comorbidities such as congestive heart failure (CHF, presence of systolic or diastolic dysfunction on transthoracic echocardiogram), diabetes mellitus (DM, fasting blood sugar $\geq 126$ $\mathrm{mg} / \mathrm{dL}$ or hemoglobin $\mathrm{A}_{1} \mathrm{C} \geq 6.5 \%$ ), peripheral arterial disease (PAD), cerebrovascular accident (CVA), and transient ischemic attack (TIA) at baseline. The presence of CAD was determined based on the history of previously documented myocardial infarction, coronary artery stent placement, or coronary artery bypass surgery. Patients were also stratified based on their renal function and body mass index (BMI). Renal function was determined by calculating estimated glomerular filtration rate (eGFR, $\mathrm{mL} / \mathrm{min} / 1.73 \mathrm{~m}^{2}$ ) using the CockcroftGault equation, with grades 1 to 5 assigned to creatinine clearances $\geq 90,60$ to 89,30 to 59,16 to 29 , and $\leq 15 \mathrm{~mL}$ / $\mathrm{min} / 1.73 \mathrm{~m}^{2}$, respectively. BMI was determined by $\mathrm{kg} / \mathrm{m}^{2}$, and patients were divided into four groups: $<18.5,18.5$ to 25 , 25.1 to $35,>35 \mathrm{~kg} / \mathrm{m}^{2}$. The laboratory data such as B-type natriuretic peptide (BNP) and peak troponin levels during the hospitalization were obtained for each patient. The troponin levels were obtained every 8 hours from the presentation of
ACS until the peak was reached, including post-CC. The Siemens Immulite 1000 (Erlangen, Germany) troponin I (99th percentile: $0.19 \mu \mathrm{g} / \mathrm{L}, \mathrm{CV}$ at 99 th percentile: $11, \mathrm{CV}$ at 10th percentile: 0.22 , with reference range being $0.01-0.19$ ) and Siemens ADVIA Centaur BNP (reference $<100 \mathrm{ng} / \mathrm{L}$ ) assays were used. The daily use of aspirin, statin, $\beta$-blockers, calcium channel blockers, and angiotensin converting enzyme inhibitors (ACE-I) or angiotensin receptor blockers (ARB) previous to hospitalization was noted for each patient.

The number of vessels with obstructive lesions $(\geq 50 \%$ stenosis), presence of lesions with $<50 \%, 50$ to $70 \%$, or $>70 \%$ stenosis in the major epicardial arteries (i.e., left main, left circumflex, left anterior descending, right main, and right posterior descending) and minor epicardial arteries (i.e., obtuse marginal, diagonal, and ramus) were noted for each patient from the CC reports. In our institution, the calculation of SYNTAX score is performed using an algorithm and is standard in these reports. ${ }^{15}$ The mean peak troponin levels were compared in patients with the presence or absence of aforementioned variables.

Statistical analysis was done using IBM SPSS Statistics 20. Univariate analysis was performed using the chi-square test for categorical and ordinal variables, and analysis of variance or Student $t$-test for continuous variables. Pearson correlation was done to determine correlation between statistically significant continuous variables and peak troponin levels. All risk factors with two-sided $p<0.05$ on univariate analysis were put into a multivariable linear regression model to assess combined effects, which calculated unstandardized coefficient.

\section{Results}

A total of 219 patients were included in the study. CV risk factors, age, gender, BMI, eGFR, lesion characteristics, and biochemical markers for our patient population are summarized in - Table 1.

- Table 2 shows the peak troponin levels in patients with major risk factors, comorbidities, and lesion characteristics, and displays the findings of univariate analysis between the groups of patients.

Subsequently, multivariable linear regression analyses were performed to determine the association of peak troponin levels with cardiovascular risk factors, lesion characteristics, SYNTAX score, and laboratory data. Variables included in the regression analysis were history of smoking, CAD, hypertension, hypercholesterolemia, BMI, age, eGFR, DM, gender, aspirin use, statin use, STEMI, NSTEMI, UA, intervention (stent or angioplasty), and all the lesion characteristics that were significant in univariate analysis.

The presence of STEMI (STEMI, $p=0.001, \beta=65.16$ ) and increasing SYNTAX score $(p=0.002, \beta=1.15)$ were associated with higher peak troponin levels. The Pearson correlation between SYNTAX score and peak troponin levels was $r=0.257(p=0.001)$. History of prior aspirin use was associated with lower peak troponin levels $(p=0.002, \beta=$ -24.32). Prior statin use and the presence of CV risk factors were not associated with peak troponin levels. 
56 Coronary Artery Disease Complexity and Peak Troponin Elevation Bhatt et al.

Table 1 Characteristics of the patient population

\begin{tabular}{|c|c|}
\hline Risk factors & $\begin{array}{l}\text { Number, } n(\%) \\
219 \text { patients }\end{array}$ \\
\hline Hypertension & $165(75 \%)$ \\
\hline Smoking & $105(48 \%)$ \\
\hline Hypercholesterolemia & $125(57 \%)$ \\
\hline \multicolumn{2}{|l|}{ BMI $\left(\mathrm{kg} / \mathrm{m}^{2}\right)$} \\
\hline$<18.5$ & $5(2 \%)$ \\
\hline $18.5-25$ & $60(27 \%)$ \\
\hline $25.1-30$ & $75(35 \%)$ \\
\hline $30.1-35$ & $44(20 \%)$ \\
\hline$>35$ & $35(16 \%)$ \\
\hline \multicolumn{2}{|l|}{ eGFR $\left(\mathrm{mL} / \mathrm{min} / 1.73 \mathrm{~m}^{2}\right)$} \\
\hline$\geq 90$ & $86(40 \%)$ \\
\hline $60-89$ & $62(28 \%)$ \\
\hline $30-59$ & $51(23 \%)$ \\
\hline $16-29$ & $11(5 \%)$ \\
\hline$\leq 15$ & $9(4 \%)$ \\
\hline Diabetes mellitus & $86(39 \%)$ \\
\hline \multicolumn{2}{|l|}{ Gender } \\
\hline Male & $134(61 \%)$ \\
\hline Female & 85 (39\%) \\
\hline \multicolumn{2}{|l|}{ Age $(y)$} \\
\hline$\leq 50$ & $28(13 \%)$ \\
\hline $51-70$ & $112(52 \%)$ \\
\hline$\geq 71$ & $79(35 \%)$ \\
\hline Coronary artery disease & $64(29 \%)$ \\
\hline Congestive heart failure & $79(36 \%)$ \\
\hline Peripheral arterial disease & $13(6 \%)$ \\
\hline CVA/TIA & $9(4 \%)$ \\
\hline STEMI & $60(27 \%)$ \\
\hline NSTEMI & $96(44 \%)$ \\
\hline Unstable angina & $63(29 \%)$ \\
\hline \multicolumn{2}{|l|}{ Vessels with coronary artery disease } \\
\hline 0 & $42(19 \%)$ \\
\hline 1 & $63(29 \%)$ \\
\hline 2 & $58(27 \%)$ \\
\hline 3 & $56(25 \%)$ \\
\hline \multicolumn{2}{|l|}{ Lesion characteristics } \\
\hline Lesions with $>70 \%$ stenosis in major epicardial arteries & $145(66 \%)$ \\
\hline Lesions with $>70 \%$ stenosis in minor epicardial arteries & $87(40 \%)$ \\
\hline Lesions with $50-70 \%$ stenosis in major epicardial arteries & $62(28 \%)$ \\
\hline Lesions with $50-70 \%$ stenosis in minor epicardial arteries & $37(17 \%)$ \\
\hline Lesions with $<50 \%$ stenosis in epicardial arteries & $149(68 \%)$ \\
\hline Arteries with diffuse disease & $119(54 \%)$ \\
\hline Calcified lesions & $40(18 \%)$ \\
\hline
\end{tabular}


Table 1 (Continued)

\begin{tabular}{|l|l|}
\hline Risk factors & $\begin{array}{l}\text { Number, } \boldsymbol{n} \text { (\%) } \\
219 \text { patients }\end{array}$ \\
\hline Bifurcation lesions & $20(9 \%)$ \\
\hline Angioplasty & $22(9 \%)$ \\
\hline Stent placement & $104(47 \%)$ \\
\hline Aspirin & $107(49 \%)$ \\
\hline Statin & $89(41 \%)$ \\
\hline Beta-blocker & $105(48 \%)$ \\
\hline ACE-inhibitor & $69(31 \%)$ \\
\hline Calcium channel blocker & $31(17 \%)$ \\
\hline BNP $(\mathrm{pg} / \mathrm{mL})$ & 180 patients \\
\hline$<100$ & $88(40 \%)$ \\
\hline$\geq 100$ & $92(60 \%)$ \\
\hline SYNTAX score & \\
\hline$<7$ & $63(29 \%)$ \\
\hline $7-14$ & $67(30 \%)$ \\
\hline$>14$ & $89(41 \%)$ \\
\hline
\end{tabular}

Abbreviations: ACE, angiotensin converting enzyme; BMI, body mass index; BNP, B-type natriuretic peptide; CVA, cerebrovascular event; eGFR, estimated glomerular filtration rate; NSTEMI, non-ST elevation myocardial infarction; STEMI, ST-elevation myocardial infarction; SYNTAX, synergy between percutaneous coronary intervention with Taxus and cardiac surgery; TIA, transient ischemic attack.

\section{Discussion}

In this study, presence of STEMI, prior aspirin use, and increasing SYNTAX score were associated with greater peak troponin level. There was a positive correlation between SYNTAX score and peak troponin level in ACS.

In ACS, the disruption of coronary artery atherosclerotic plaque leads to thrombosis which results in acute myocardial ischemia. ${ }^{18}$ Troponin leak occurs from myocardial injury and subsequent reperfusion to the ischemic myocardium postrevascularization. In our study, the patients with STEMI had significantly greater $(p=0.001, \beta=65.16)$ peak troponin levels compared with those without STEMI. This is likely due to the transmural myocardial injury that occurs in the setting of STEMI. ${ }^{19}$ Patients with STEMI have a persistent and complete occlusion of an epicardial artery putting a large myocardial territory at risk of ischemia. ${ }^{4}$ In contrast, NSTEMI and UA results from varying degree of coronary obstruction, but without a complete occlusion of the vessel. ${ }^{20}$ The greater the area of infarct, the greater the troponin leak occurs from myocardial necrosis. ${ }^{20}$ In our study, the smaller degree of peak troponin levels in patients with NSTEMI or UA compared with those without NSTEMI or UA is likely due to STEMI. Our findings suggest that patients with STEMI should be monitored very closely in hospital and postdischarge due to higher likelihood of elevated peak troponins and the associated potentially increased risk of CV mortality and adverse events.

In patients with stable CAD, progressive elevation in troponin level has been seen with increasing severity of obstructive and multivessel CAD. ${ }^{21}$ The presence of tropo- nin has been associated with increased prevalence of triple vessel disease, left main disease, and greater degree of lesion obstruction in patients with UA. ${ }^{11,12}$ Similarly, higher troponin levels have been associated with the presence of thrombus and persistent occlusions in patients with UA and NSTEMI. ${ }^{22}$ But, there is lack of data on association of peak troponin levels and severity of CAD in patients with ACS including STEMI, NSTEMI, and UA collectively. In our study, there was an increase in levels of peak troponins in patients with the presence of obstructive vessels compared with those with no vessel disease. Although, there was a slight increase in peak troponin among patients with triple vessel disease compared with those with a single or double vessel disease, there was no difference in peak troponin among those with single and double vessel disease. Overall, the difference in peak troponin levels was significant on univariate analysis ( $p=0.021$ ), but was not independently associated with the number of obstructive vessels in multivariate analysis. Similarly, we noted greater peak troponin levels in patients with the presence of lesions with $>70 \%$ stenosis in major and minor epicardial vessels compared with those without these lesions. The association of these lesions and peak troponin was significant on univariate analysis, but became insignificant on multivariate analysis, which suggests that the degree of peak troponin elevation was driven by factors other than the severity of lesion stenosis. We did not find any association of lesions with $<50 \%$ and 50 to $70 \%$ stenosis and peak troponin levels in ACS. In contrast to previous studies discussed above, our study also provides more comprehensive assessment of ACS by including STEMI, NSTEMI, and UA and determining peak 
58 Coronary Artery Disease Complexity and Peak Troponin Elevation Bhatt et al.

Table 2 Univariate analysis of peak troponin, cardiovascular risk factors, and lesion characteristics

\begin{tabular}{|c|c|c|c|c|c|}
\hline Risk factors & $\begin{array}{l}\text { Peak troponin } \\
\text { Mean } \pm S D(\mathrm{ng} / \mathrm{mL})\end{array}$ & SEM & $\begin{array}{l}\text { Difference } \\
\text { of mean }\end{array}$ & $\begin{array}{l}95 \% \mathrm{Cl} \text { of mean } \\
\text { or difference } \\
\text { of mean }\end{array}$ & $p$-Value \\
\hline \multicolumn{6}{|l|}{ Hypertension } \\
\hline Present $(n=165)$ & $23.96 \pm 50.22$ & 3.91 & 12.31 & $(-3.50)$ to 28.12 & 0.126 \\
\hline Absent $(n=54)$ & $36.27 \pm 54.03$ & 7.35 & & & \\
\hline \multicolumn{6}{|l|}{ Smoking } \\
\hline Present $(n=105)$ & $29.05 \pm 56.74$ & 5.54 & -3.95 & $(-17.66)$ to 9.75 & 0.570 \\
\hline Absent $(n=114)$ & $25.10 \pm 45.97$ & 4.30 & & & \\
\hline \multicolumn{6}{|l|}{ Hypercholesterolemia } \\
\hline Present $(n=125)$ & $24.35 \pm 44.99$ & 4.02 & 6.48 & $(-7.40)$ to 20.36 & 0.359 \\
\hline Absent $(n=94)$ & $30.83 \pm 59.03$ & 6.12 & & & \\
\hline \multicolumn{6}{|c|}{ Group body mass index $\left(\mathrm{kg} / \mathrm{m}^{2}\right)$} \\
\hline 1 & $<18.5(n=5)$ & $2.85 \pm 3.20$ & 1.43 & $(-1.11)$ to 6.83 & 0.624 \\
\hline 2 & $18.5-25(n=60)$ & $31.72 \pm 53.47$ & 6.90 & 17.91 to 45.54 & \\
\hline 3 & $25.1-30(n=75)$ & $24.38 \pm 45.86$ & 5.29 & 13.83 to 34.94 & \\
\hline 4 & $30.1-35(n=44)$ & $22.73 \pm 43.60$ & 6.57 & 9.47 to 35.99 & \\
\hline 5 & $>35(n=35)$ & $33.28 \pm 68.89$ & 11.64 & 9.62 to 56.95 & \\
\hline \multicolumn{6}{|c|}{ Grade eGFR $\left(\mathrm{mL} / \mathrm{min} / 1.73 \mathrm{~m}^{2}\right)$} \\
\hline 1 & $\geq 90(n=86)$ & $22.71 \pm 51.65$ & 5.57 & 11.63 to 33.78 & 0.489 \\
\hline 2 & $60-89(n=62)$ & $30.37 \pm 49.30$ & 6.26 & 17.85 to 42.89 & \\
\hline 3 & $30-59(n=51)$ & $33.24 \pm 56.42$ & 7.90 & 17.37 to 49.11 & \\
\hline 4 & $16-29(n=11)$ & $31.11 \pm 55.63$ & 16.77 & $(-6.26)$ to 68.48 & \\
\hline 5 & $\leq 15(n=9)$ & $4.32 \pm 4.92$ & 1.64 & 0.54 to 8.11 & \\
\hline \multicolumn{6}{|l|}{ Diabetes mellitus } \\
\hline Present $(n=86)$ & $22.51 \pm 52.28$ & 5.64 & 7.38 & $(-6.61)$ to 21.38 & 0.299 \\
\hline Absent $(n=133)$ & $29.90 \pm 50.70$ & 4.39 & & & \\
\hline \multicolumn{6}{|l|}{ Gender } \\
\hline Male $(n=134)$ & $31.89 \pm 57.52$ & 4.97 & -12.61 & $(-25.44)$ to $(0.21)$ & 0.054 \\
\hline Female $(n=85)$ & $19.28 \pm 38.74$ & 4.20 & & & \\
\hline \multicolumn{6}{|l|}{ Age (y) } \\
\hline$\leq 50(n=28)$ & $20.44 \pm 28.80$ & 5.44 & & 9.27 to 31.61 & 0.394 \\
\hline $51-70(n=112)$ & $30.79 \pm 58.61$ & 5.48 & & 19.92 to 41.67 & \\
\hline$\geq 71(n=79)$ & $21.84 \pm 44.83$ & 5.01 & & 11.86 to 31.81 & \\
\hline \multicolumn{6}{|c|}{ Coronary artery disease } \\
\hline Present $(n=64)$ & $17.68 \pm 38.31$ & 4.79 & 13.16 & 0.25 to 26.08 & $0.046^{\mathrm{a}}$ \\
\hline Absent $(n=155)$ & $30.84 \pm 55.49$ & 4.46 & & & \\
\hline \multicolumn{6}{|c|}{ Congestive heart failure } \\
\hline Present $(n=140)$ & $22.54 \pm 45.66$ & 4.17 & -13.89 & $(-29.82)$ to 2.03 & 0.087 \\
\hline Absent $(n=79)$ & $36.43 \pm 61.24$ & 6.89 & & & \\
\hline \multicolumn{6}{|c|}{ Peripheral arterial disease } \\
\hline Present $(n=13)$ & $10.99 \pm 13.94$ & 3.87 & 17.01 & 6.25 to 27.77 & $0.003^{\mathrm{a}}$ \\
\hline Absent $(n=206)$ & $28.00 \pm 52.67$ & 3.67 & & & \\
\hline \multicolumn{6}{|l|}{ CVA/TIA } \\
\hline Present $(n=9)$ & $9.29 \pm 7.91$ & 2.64 & 18.46 & 9.52 to 27.41 & $0.001^{a}$ \\
\hline
\end{tabular}


Table 2 (Continued)

\begin{tabular}{|c|c|c|c|c|c|}
\hline Risk factors & $\begin{array}{l}\text { Peak troponin } \\
\text { Mean } \pm S D(\mathrm{ng} / \mathrm{mL})\end{array}$ & SEM & $\begin{array}{l}\text { Difference } \\
\text { of mean }\end{array}$ & $\begin{array}{l}95 \% \mathrm{Cl} \text { of mean } \\
\text { or difference } \\
\text { of mean }\end{array}$ & $p$-Value \\
\hline Absent $(n=210)$ & $27.75 \pm 52.27$ & 3.60 & & & \\
\hline \multicolumn{6}{|l|}{ STEMI } \\
\hline Present $(n=60)$ & $76.22 \pm 74.98$ & 10.01 & -66.82 & $(-87.16)$ to $(-46.48)$ & $0.001^{\mathrm{a}}$ \\
\hline Absent $(n=159)$ & $9.41 \pm 21.76$ & 1.68 & & & \\
\hline \multicolumn{6}{|l|}{ NSTEMI } \\
\hline Present $(n=96)$ & $12.42 \pm 24.49$ & 2.28 & 28.72 & 15.33 to 42.10 & $0.001^{\mathrm{a}}$ \\
\hline Absent $(n=123)$ & $41.14 \pm 65.88$ & 6.36 & & & \\
\hline \multicolumn{6}{|l|}{ Unstable angina } \\
\hline Present $(n=63)$ & $10.48 \pm 29.46$ & 3.62 & 22.46 & 11.04 to 33.89 & $0.001^{\mathrm{a}}$ \\
\hline Absent $(n=156)$ & $32.94 \pm 56.48$ & 4.52 & & & \\
\hline \multicolumn{6}{|c|}{ Number of obstructive vessels } \\
\hline 0 vessel $(n=42)$ & $5.50 \pm 8.33$ & 1.28 & & 2.91 to 8.10 & $0.021^{\mathrm{a}}$ \\
\hline 1 vessel $(n=63)$ & $30.36 \pm 64.31$ & 8.10 & & 14.17 to 46.56 & \\
\hline 2 vessels $(n=58)$ & $30.11 \pm 42.85$ & 5.62 & & 18.85 to 41.38 & \\
\hline 3 vessels $(n=56)$ & $36.10 \pm 58.03$ & 7.75 & & 20.56 to 51.64 & \\
\hline \multicolumn{6}{|c|}{ Lesions with $>70 \%$ stenosis in the major epicardial arteries } \\
\hline Present $(n=145)$ & $34.98 \pm 54.43$ & 4.52 & -23.64 & $(-36.54)$ to $(-10.74)$ & $0.001^{\mathrm{a}}$ \\
\hline Absent $(n=74)$ & $11.34 \pm 40.63$ & 4.72 & & & \\
\hline \multicolumn{6}{|c|}{ Lesions with $>70 \%$ stenosis in minor epicardial arteries } \\
\hline Present $(n=87)$ & $37.00 \pm 62.11$ & 6.65 & -16.60 & $(-31.60)$ to $(-1.60)$ & $0.030^{\mathrm{a}}$ \\
\hline Absent $(n=132)$ & $20.40 \pm 41.74$ & 3.63 & & & \\
\hline \multicolumn{6}{|c|}{ Lesions with $50-70 \%$ stenosis in the major epicardial arteries } \\
\hline Present $(n=62)$ & $27.28 \pm 42.96$ & 5.45 & -0.39 & $(-15.60)$ to $(14.81)$ & 0.959 \\
\hline Absent $(n=157)$ & $26.88 \pm 54.41$ & 4.34 & & & \\
\hline \multicolumn{6}{|c|}{ Lesions with $50-70 \%$ stenosis in the minor epicardial arteries } \\
\hline Present $(n=37)$ & $30.78 \pm 55.55$ & 9.13 & -4.56 & $(-22.83)$ to 13.72 & 0.624 \\
\hline Absent $(n=182)$ & $26.22 \pm 50.56$ & 3.74 & & & \\
\hline \multicolumn{6}{|c|}{ Lesions with $<50 \%$ stenosis } \\
\hline Present $(n=149)$ & $30.41 \pm 56.76$ & 4.65 & -10.68 & $(-23.26)$ to $(1.9)$ & 0.096 \\
\hline Absent $(n=70)$ & $19.73 \pm 36.55$ & 4.36 & & & \\
\hline \multicolumn{6}{|c|}{ Vessels with diffuse disease } \\
\hline Present $(n=119)$ & $25.37 \pm 47.07$ & 4.31 & 3.56 & $(-10.19)$ to $(17.30)$ & 0.610 \\
\hline Absent $(n=100)$ & $28.93 \pm 56.17$ & 5.61 & & & \\
\hline \multicolumn{6}{|l|}{ Calcified lesions } \\
\hline Present $(n=40)$ & $15.23 \pm 35.49$ & 5.61 & 14.04 & 0.28 to 27.80 & $0.046^{a}$ \\
\hline Absent $(n=179)$ & $29.27 \pm 54.01$ & 4.04 & & & \\
\hline \multicolumn{6}{|l|}{ Bifurcation lesions } \\
\hline Present $(n=20)$ & $36.31 \pm 51.53$ & 11.52 & -19.29 & $(-34.00)$ to 13.49 & 0.396 \\
\hline Absent $(n=199)$ & $26.06 \pm 51.35$ & 3.64 & & & \\
\hline \multicolumn{6}{|l|}{ Angioplasty } \\
\hline Present $(n=22)$ & $44.41 \pm 64.07$ & 13.98 & -19.13 & $(-48.99)$ to 10.73 & 0.198 \\
\hline Absent $(n=197)$ & $25.27 \pm 49.73$ & 3.54 & & & \\
\hline
\end{tabular}


Table 2 (Continued)

\begin{tabular}{|c|c|c|c|c|c|}
\hline Risk factors & $\begin{array}{l}\text { Peak troponin } \\
\text { Mean } \pm \mathrm{SD}(\mathrm{ng} / \mathrm{mL})\end{array}$ & SEM & $\begin{array}{l}\text { Difference } \\
\text { of mean }\end{array}$ & $\begin{array}{l}95 \% \mathrm{Cl} \text { of mean } \\
\text { or difference } \\
\text { of mean }\end{array}$ & $p$-Value \\
\hline \multicolumn{6}{|l|}{ Stent placement } \\
\hline Present $(n=104)$ & $43.76 \pm 65.17$ & 6.39 & -31.83 & $(-45.41)$ to $(-18.24)$ & $0.001^{\mathrm{a}}$ \\
\hline Absent $(n=114)$ & $11.93 \pm 26.80$ & 2.51 & & & \\
\hline \multicolumn{6}{|l|}{ Aspirin } \\
\hline Present $(n=107)$ & $12.02 \pm 25.37$ & 2.45 & 29.62 & 16.58 to 42.66 & $0.001^{\mathrm{a}}$ \\
\hline Absent $(n=112)$ & $41.64 \pm 64.52$ & 6.12 & & & \\
\hline \multicolumn{6}{|l|}{ Statin } \\
\hline Present $(n=89)$ & $17.52 \pm 39.34$ & 4.17 & 16.20 & 3.27 to 29.13 & $0.014^{\mathrm{a}}$ \\
\hline Absent $(n=129)$ & $33.72 \pm 57.55$ & 5.07 & & & \\
\hline \multicolumn{6}{|l|}{ Beta-blocker } \\
\hline Present $(n=105)$ & $23.81 \pm 52.87$ & 5.16 & 6.11 & $(-7.58)$ to 19.80 & 0.380 \\
\hline Absent $(n=114)$ & $29.93 \pm 49.93$ & 4.67 & & & \\
\hline \multicolumn{6}{|l|}{ ACE-inhibitor } \\
\hline Present $(n=69)$ & $28.96 \pm 65.01$ & 7.88 & -2.69 & $(-17.54)$ to 12.50 & 0.721 \\
\hline Absent $(n=150)$ & $26.26 \pm 44.15$ & 3.60 & & & \\
\hline \multicolumn{6}{|c|}{ Calcium channel blocker } \\
\hline Present $(n=31)$ & $16.97 \pm 37.35$ & 6.82 & 11.75 & $(-8.16)$ to 31.66 & 0.246 \\
\hline Absent $(n=188)$ & $28.72 \pm 53.23$ & 3.88 & & & \\
\hline \multicolumn{6}{|l|}{$\mathrm{BNP}(\mathrm{pg} / \mathrm{mL}, n=180)$} \\
\hline$<100(n=88)$ & $28.29 \pm 48.57$ & 5.18 & & 18.00 to 38.59 & 0.762 \\
\hline$\geq 100(n=92)$ & $30.76 \pm 59.56$ & 6.21 & & 18.43 to 43.10 & \\
\hline \multicolumn{6}{|l|}{ SYNTAX score } \\
\hline $1-6(n=63)$ & $9.62 \pm 27.35$ & 4.03 & & 1.49 to 17.74 & $0.035^{\mathrm{a}}$ \\
\hline $7-14(n=67)$ & $28.48 \pm 52.57$ & 7.43 & & 13.54 to 43.42 & \\
\hline$>14(n=89)$ & $50.01 \pm 67.51$ & 8.01 & & 34.03 to 65.99 & \\
\hline
\end{tabular}

Abbreviations: ACE, angiotensin converting enzyme; BMI, body mass index; BNP, B-type natriuretic peptide; CVA, cerebrovascular event; eGFR, estimated glomerular filtration rate; NSTEMI, non ST elevation myocardial infarction; SD, standard deviation; SEM, standard error of mean; STEMI, ST elevation myocardial infarction; SYNTAX, synergy between percutaneous coronary intervention with Taxus and cardiac surgery; TIA, transient ischemic attack. a $p<0.05$.

troponin levels, which gives better estimation of myocardial injury compared with one time troponin measurement done in these studies. Presence of noncalcified plaques has been associated with greater troponin levels than calcified plaques in patients with stable CAD. ${ }^{23}$ In our study, absence of calcified lesions was associated with greater peak troponin levels on univariate analysis $(p=0.046)$. But, the absence of association on multivariate analysis suggests that this relationship may be mediated by confounding factors. We did not find any association between peak troponins and lesions with diffuse disease and bifurcation lesions. Our findings suggest that understanding of an association of peak troponin levels and CAD may require looking beyond just the presence of number of obstructive lesions and vessels.
Increasing troponin level has been associated with increase in SYNTAX score in NSTEMI. ${ }^{17}$ But, in that study the troponin levels were looked at the baseline and the association between troponin and SYNTAX score was only significant on univariate analysis. Both peak troponin level and SYNTAX score have been associated with long-term mortality and adverse cardiovascular events in ACS. ${ }^{5,6,16,17}$ SYNTAX score has been associated with troponin level in diabetic patients with stable $\mathrm{CAD}^{24}$; however, their association in patients with ACS remains unknown. Our study shows that there was a gradual increase in peak troponin with increasing SYNTAX scores (-Fig. 1). This difference was significant on multivariate analysis $(p=0.002, \beta=1.15)$ and was independent of angioplasty or stent placement during CC. There was a significant positive correlation between SYNTAX score and 


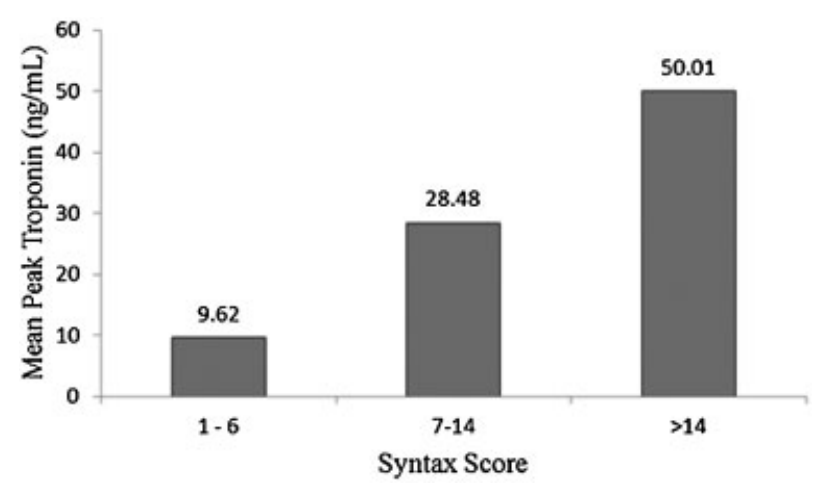

Fig. 1 Shows the comparison of peak troponin level among patients in different categories of SYNTAX score. There were 63, 67, and 89 patients with SYNTAX score 1 to 6,7 to 14 , and $>14$, respectively. SYNTAX, synergy between percutaneous coronary intervention with Taxus and cardiac surgery.

peak troponin elevation $(r=0.257(p=0.001)$. Our study shows a positive association between the two prognostic indicators (i.e., SNYTAX score and peak troponin levels) in ACS. These findings suggest that patients with greater complexity and severity of CAD are at an increased risk for myocardial ischemia, as shown with greater peak troponin levels. We did not find an association of elevated troponin level and angioplasty or stent placement in the setting of ACS. The presence of elevated troponin level in patients with ACS in univariate analysis is likely driven by the complexity of lesion and the resulting intervention. Our results highlight the importance of incorporating the complexity of CAD, beyond the severity of CAD described just based on the number of obstructive vessels, when predicting the peak troponin levels in ACS.

We did not find any association between typical cardiovascular risk factors such as hypertension, smoking, hypercholesterolemia, BMI, renal function, age, DM, gender, and CHF with peak troponin level. Worsening renal function has been associated with troponin elevation in patients without myocardial ischemia. ${ }^{25}$ Although the pathophysiology remains unclear, the role of uremic myopathy leading to rhabdomyolysis, decreased troponin clearance, and hypertrophic cardiomyopathy have been suggested. ${ }^{25-27}$ Dessap et al, in a study of 125 patients with acute myocardial infarction found no association between creatinine clearance and peak troponin levels. ${ }^{25}$ Similarly, we noticed a trend of increase in peak troponin levels until grade 3 renal function, but the trend disappears in grades 4 and 5 renal function. There was no association of renal function and peak troponin levels in our study. However, our study not only had a larger sample size, but we also provided more comprehensive assessment of coronary lesion characteristics and $\mathrm{CV}$ risk factor profile of our sample. These findings suggest that although troponin levels are influenced by renal function, but in the setting of ACS the myocardial ischemia may potentially mitigate the association of renal impairment and peak troponin levels.

Although chronic $\mathrm{CHF}$ is associated with elevated baseline troponin levels, ${ }^{28}$ the contribution of baseline troponin levels to peak troponin elevation in the setting of ACS and CHF remains questionable. Similarly, in our study BNP level did not predict peak troponin in the setting of ACS. Although, chronic CHF leads to both elevated $\mathrm{BNP}^{29}$ and cardiomyocyte injury, ${ }^{30}$ the association of BNP and peak troponin elevation in ACS may be confounded by cardiomyocyte injury resulting from coronary lesion thrombosis. It is also difficult to explain the association of the absence of CVA/TIA and PAD with elevated peak troponin considering the small sample size of 9 and 13 , respectively, in univariate analysis. The patients with history of CAD had a lower peak troponin compared with patients without prior CAD on univariate analysis. It is likely due to the reduced proportion of viable myocardium before ACS in patients with prior CAD compared with patients with no history of CAD. Although, nonsignificant on multivariate analysis, this association is interesting and warrants further investigation.

Both aspirin and statin have been recommended for primary and secondary prevention in patients at high risk for CV events. ${ }^{31,32}$ Aspirin use has been associated with reduced risk of nonfatal myocardial infarction, cardiac and all-cause mortality. ${ }^{33-35}$ However, the degree to which aspirin use predicts peak troponin in ACS remains unknown. In our study, the patients who were on daily aspirin before presenting with ACS had significantly lower mean peak troponin level compared with those without daily aspirin use and ACS (12.0 vs. 41.6, $p=0.001$ ); this association was significant on multivariate analysis $(p=0.002, \beta=-24.32)$. The rupture of fibrinous cap of atherosclerotic plaque leads to a sequence of inflammatory reactions that promote platelet aggregation and intraluminal thrombus formation. ${ }^{18,36,37}$ The platelets, besides contributing to the acute thrombotic vascular occlusion, also participate in the inflammatory reactions leading to ACS. ${ }^{18,38}$ Aspirin, by inhibiting platelet aggregation $^{33,35}$ prevents thrombus formation and would potentially lessen the degree of vascular occlusion in ACS; hence, minimizing the myocardial territory at risk of ischemia. In our study, the protective effect of daily aspirin use was reflected by the reduced level of peak troponin in patients who were on aspirin compared with those without daily aspirin use. We recommend that patients who present with ACS in the absence of daily aspirin use should be monitored more closely in-hospital and thereafter, due to increased mortality and morbidity risk associated with greater peak troponin level.

Statins play an important role in stabilizing the atherosclerotic plaque and preventing vascular inflammation in ACS. ${ }^{39}$ In vivo and animal models have shown that statins may mitigate thrombotic potential of coronary plaques by decreasing the level of local tissue factor antigen and inflammatory mediators..$^{39}$ In our study, although troponin level was lower in patients with history of prior use of statin, this association was not independent. Therefore, although statins unquestionably modify and stabilize atherosclerotic plaques, its role in preventing thrombosis remains uncertain. We believe that a finding of lower peak troponin in the patients with statin is likely due to other confounding factors, such as concomitant use of aspirin. In our study, prior use of $\beta$ blockers, ACE-I/ARBs or calcium channel blockers was not 
associated with peak troponin levels. In a study on NSTEMI patients, Kennon et al found that ACE-I was associated with reduced levels of peak troponin; this association was attributed to the anti-inflammatory and possible antithrombotic properties of ACE-I. ${ }^{40}$ Besides limiting their sample to NSTEMI, they did not study the severity and complexity of coronary lesions and comprehensive CV risk factor profile of subjects in their study. Based on our findings and lack of adequate literature to support the association of ACE-I and troponins in ACS, we recommend further studies.

Since we looked at the CV risk factors at baseline, the preventive effect of the above medications could have confounded the association of the risk factor profile and peak troponin in our patients. ACE inhibitors are known to slow the progression of chronic kidney disease (CKD) by preserving $\mathrm{eGFR}^{41}$; whether the use of ACE inhibitors in patients with CKD confounds the association of CKD and peak troponin levels remains unknown. A similar explanation holds true for statins, as they are known to reduce the rate of decline in renal function in patients with CKD and CV disease. ${ }^{42}$

In our study, CV risk factors and comorbidities were only assessed at baseline. This study did not address the association of severity and control of CV risk factors with peak troponin levels. The retrospective nature of the study meant that patient data were solely obtained from chart review. Counteracting this limitation is the consistency with which the $\mathrm{CC}$ reports are documented in our institution, which lends credibility to these findings. Angiographic interpretation of coronary arteries (such as lesion characteristics and SYNTAX score) was limited to an experienced interventional cardiologist, which eliminates the interobserver variability. In conclusion, our study demonstrates that peak troponin, an important prognostic indicator in ACS, would less likely be determined by a CV risk profile of an individual patient. The important predictors of peak troponin level are the severity and complexity of CAD, acuity of the event (i.e., STEMI) requiring urgent $\mathrm{CC}$ and prior use of antiplatelet agents such as aspirin. Our study will help predict the patient population who are likely to develop higher peak troponin levels, potentially increasing their risk for future adverse cardiac events, ultimately requiring close monitoring inhospital, and follow-up thereafter. We recommend prospective studies are needed to validate our findings.

\section{Conflict of Interest}

The authors report no financial relationships or conflicts of interest regarding the content herein.

\section{Acknowledgment}

None.

\section{Note}

All authors made substantial contributions to the following: (1) conception and design, or acquisition of data, or analysis and interpretation of data; (2) drafting the article; and (3) final approval of the version to be published.

\section{References}

1 Kumar A, Cannon CP. Acute coronary syndromes: diagnosis and management, part I. Mayo Clin Proc 2009;84(10):917-938

2 Daubert MA, Jeremias A. The utility of troponin measurement to detect myocardial infarction: review of the current findings. Vasc Health Risk Manag 2010;6:691-699

3 Antman EM, Morrow DA. Biomarker release after percutaneous coronary intervention: a message from the heart. Circ Cardiovasc Interv 2008;1(1):3-6

4 de Winter RJ, Tijssen JG. Non-ST-segment elevation myocardial infarction: revascularization for everyone? JACC Cardiovasc Interv 2012;5(9):903-905

5 Hamm CW, Braunwald E. A classification of unstable angina revisited. Circulation 2000;102(1):118-122

6 Tricoci P, Leonardi S, White J, et al. Cardiac troponin after percutaneous coronary intervention and 1-year mortality in non-STsegment elevation acute coronary syndrome using systematic evaluation of biomarker trends. J Am Coll Cardiol 2013;62(3): 242-251

7 Chin CT, Wang TY, Li S, et al. Comparison of the prognostic value of peak creatine kinase-MB and troponin levels among patients with acute myocardial infarction: a report from the Acute Coronary Treatment and Intervention Outcomes Network Registry-get with the guidelines. Clin Cardiol 2012;35(7):424-429

8 Kontos MC, Shah R, Fritz LM, et al. Implication of different cardiac troponin I levels for clinical outcomes and prognosis of acute chest pain patients. J Am Coll Cardiol 2004;43(6):958-965

9 Boden H, Ahmed TA, Velders MA, et al. Peak and fixed-time highsensitive troponin for prediction of infarct size, impaired left ventricular function, and adverse outcomes in patients with first ST-segment elevation myocardial infarction receiving percutaneous coronary intervention. Am J Cardiol 2013;111(10): 1387-1393

10 Byrne RA, Ndrepepa G, Braun S, et al. Peak cardiac troponin-T level, scintigraphic myocardial infarct size and one-year prognosis in patients undergoing primary percutaneous coronary intervention for acute myocardial infarction. Am J Cardiol 2010;106(9): $1212-1217$

11 Frey N, Dietz A, Kurowski V, et al. Angiographic correlates of a positive troponin $T$ test in patients with unstable angina. Crit Care Med 2001;29(6):1130-1136

12 Jurlander B, Farhi ER, Banas JJ Jr, et al. Coronary angiographic findings and troponin $\mathrm{T}$ in patients with unstable angina pectoris. Am J Cardiol 2000;85(7):810-814

13 Capodanno D, Capranzano P, Di Salvo ME, et al. Usefulness of SYNTAX score to select patients with left main coronary artery disease to be treated with coronary artery bypass graft. JACC Cardiovasc Interv 2009;2(8):731-738

14 Head SJ, Farooq V, Serruys PW, Kappetein AP. The SYNTAX score and its clinical implications. Heart 2014;100(2):169-177

15 Sianos G, Morel MA, Kappetein AP, et al. The SYNTAX Score: an angiographic tool grading the complexity of coronary artery disease. EuroIntervention 2005;1(2):219-227

16 Girasis C, Garg S, Räber L, et al. SYNTAX score and Clinical SYNTAX score as predictors of very long-term clinical outcomes in patients undergoing percutaneous coronary interventions: a substudy of SIRolimus-eluting stent compared with pacliTAXel-eluting stent for coronary revascularization (SIRTAX) trial. Eur Heart J 2011; 32(24):3115-3127

17 Palmerini T, Genereux P, Caixeta A, et al. Prognostic value of the SYNTAX score in patients with acute coronary syndromes undergoing percutaneous coronary intervention: analysis from the 
ACUITY (Acute Catheterization and Urgent Intervention Triage StrategY) trial. J Am Coll Cardiol 2011;57(24):2389-2397

18 Davies MJ. The pathophysiology of acute coronary syndromes. Heart 2000;83(3):361-366

19 Gonzalez MA, Porterfield CP, Eilen DJ, et al; Multidisciplinary Atherothrombosis Prevention Program (MAPP). Quartiles of peak troponin are associated with long-term risk of death in type 1 and STEMI, but not in type 2 or NSTEMI patients. Clin Cardiol 2009;32(10):575-583

20 Antman EM. Troponin measurements in ischemic heart disease: more than just a black and white picture. J Am Coll Cardiol 2001; 38(4):987-990

21 Laufer EM, Mingels AM, Winkens MH, et al. The extent of coronary atherosclerosis is associated with increasing circulating levels of high sensitive cardiac troponin T. Arterioscler Thromb Vasc Biol 2010;30(6):1269-1275

22 Lindahl B, Diderholm E, Lagerqvist B, Venge P, Wallentin L; FRISC II (Fast Revascularization during InStability in CAD) Investigators. Mechanisms behind the prognostic value of troponin $T$ in unstable coronary artery disease: a FRISC II substudy. J Am Coll Cardiol 2001;38(4):979-986

23 Korosoglou G, Lehrke S, Mueller D, et al. Determinants of troponin release in patients with stable coronary artery disease: insights from CT angiography characteristics of atherosclerotic plaque. Heart 2011;97(10):823-831

24 Ucar H, Gur M, Seker T, et al. High-Sensitivity Cardiac Troponin T is Associated with SYNTAX Score and Diabetes Mellitus in Patients with Stable Coronary Artery Disease. J Clin Exp Cardiolog. 2013; 4(9): $1-5$

25 Mekontso Dessap A, Lellouche N, Audard V, et al. Effect of renal failure on peak troponin Ic level in patients with acute myocardial infarction. Cardiology 2008;109(4):217-221

26 Donaldson A, Cove-Smith R. Cardiac troponin levels in patients with impaired renal function. Hosp Med 2001;62(2):86-89

27 Adams GR, Vaziri ND. Skeletal muscle dysfunction in chronic renal failure: effects of exercise. Am J Physiol Renal Physiol 2006;290(4): F753-F761

28 Agzew Y. Elevated serum cardiac troponin in non-acute coronary syndrome. Clin Cardiol 2009;32(1):15-20

29 Tsai SH, Lin YY, Chu SJ, Hsu CW, Cheng SM. Interpretation and use of natriuretic peptides in non-congestive heart failure settings. Yonsei Med J 2010;51(2):151-163
30 Schaper J, Froede R, Hein S, et al. Impairment of the myocardial ultrastructure and changes of the cytoskeleton in dilated cardiomyopathy. Circulation 1991;83(2):504-514

31 Udell JA, Scirica BM, Braunwald E, et al. Statin and aspirin therapy for the prevention of cardiovascular events in patients with type 2 diabetes mellitus. Clin Cardiol 2012;35(12):722-729

32 Rich JD, Cannon CP, Murphy SA, Qin J, Giugliano RP, Braunwald E. Prior aspirin use and outcomes in acute coronary syndromes. J Am Coll Cardiol 2010;56(17):1376-1385

33 Cairns JA, Gent M, Singer J, et al. Aspirin, sulfinpyrazone, or both in unstable angina. Results of a Canadian multicenter trial. N Engl J Med 1985;313(22):1369-1375

34 Collaborative overview of randomised trials of antiplatelet therapy-I: Prevention of death, myocardial infarction, and stroke by prolonged antiplatelet therapy in various categories of patients. Antiplatelet Trialists' Collaboration. BMJ 1994;308(6921):81-106

35 Lewis HD Jr, Davis JW, Archibald DG, et al. Protective effects of aspirin against acute myocardial infarction and death in men with unstable angina. Results of a Veterans Administration Cooperative Study. N Engl J Med 1983;309(7):396-403

36 Libby P. Mechanisms of acute coronary syndromes and their implications for therapy. N Engl J Med 2013;368(21):2004-2013

37 Fuster V, Badimon L, Badimon JJ, Chesebro JH. The pathogenesis of coronary artery disease and the acute coronary syndromes (2). N Engl J Med 1992;326(5):310-318

38 Massberg S, Schulz C, Gawaz M. Role of platelets in the pathophysiology of acute coronary syndrome. Semin Vasc Med 2003; 3(2):147-162

39 Libby P. Current concepts of the pathogenesis of the acute coronary syndromes. Circulation 2001;104(3):365-372

40 Kennon S, Barakat K, Hitman GA, et al. Angiotensin-converting enzyme inhibition is associated with reduced troponin release in non-ST-elevation acute coronary syndromes. J Am Coll Cardiol 2001;38(3):724-728

41 Ruggenenti P, Perna A, Remuzzi G; Gruppo Italiano di Studi Epidemiologici in Nefrologia. ACE inhibitors to prevent end-stage renal disease: when to start and why possibly never to stop: a post hoc analysis of the REIN trial results. Ramipril Efficacy in Nephropathy. J Am Soc Nephrol 2001;12(12):2832-2837

42 Sandhu S, Wiebe N, Fried LF, Tonelli M. Statins for improving renal outcomes: a meta-analysis. J Am Soc Nephrol 2006;17(7): 2006-2016 